\title{
The effects of 0-GIcNAc alteration on Alzheimer-like neurodegeneration in SK-N-SH cells
}

\author{
Nan Ding ${ }^{\mathrm{a} \#, ~ P e n g ~ P e n g ~}{ }^{\mathrm{a} \#}$, Yu-jing Chu ${ }^{\mathrm{a}}$, Jing-jing Wang ${ }^{\mathrm{a}}$, Shu-yi Chen ${ }^{\mathrm{a}}$, Renuka Arulthas ${ }^{\mathrm{a}}$, Yan-qiu Deng ${ }^{\mathrm{a}}$
}

Background. O-GlcNAcylation is a highly dynamic post-translational modification that plays a key role in regulating phosphorylation of protein and cell survival. The proteins O-GIcNAcylation level is regulated dynamically by O-GlcNAc transferase (OGT) and $\beta$-N-acetylglucosaminidase (O-GlcNAcase, OGA). Although previous studies have suggested the role of O-GIcNAcylation in neurodegenerative diseases, the mechanism of O-GlcNAcylation in Alzheimer's disease $(A D)$ remains unclear.

Methods. The decrease of O-GIcNAcylation by alloxan, an OGT inhibitor, and increase by NAG-thiazolines (NAG-Ae), an O-GlcNAcase inhibitor were tested to investigate the effects of O-GIcNAc alteration on AD like neurodegeneration in SK-N-SH cells.

Results. The level of O-GIcNAcylation was decreased in alloxan treated cells and increased in NAG-Ae treated cells. Meanwhile, it was observed that both abnormal phosphorylation of NFs in cell bodies and apoptosis induced by alloxan treatment can be resisted by pretreatment or simultaneous treatment with appropriate NAG-Ae.

Conclusion. These results demonstrated that increasing O-GIcNAc with NAG-Ae protected AD like neurodegeneration from NFs hyperphosphorylation and the cell loss, suggesting the role of O-GlcNAc in the pathogenesis and therapy of $A D$.

Key words: O-GlcNAcylation; O-GlcNAcase; O-GlcNAc transferase; neurofilament phosphorylation; Alzheimer's disease

Received: September 18, 2017; Accepted: July 17, 2018; Available online: August 28, 2018

https://doi.org/10.5507/bp.2018.042

${ }^{a}$ Department of Pathophysiology, Basic Medical College, Tianjin Medical University, 300070, China

"These authors contributed equally to this work and should be considered co-first authors

Corresponding author: Yan-qiu Deng, e-mail:1766464240@qq.com

\section{INTRODUCTION}

Alzheimer's disease $(\mathrm{AD})$ is a common neurodegenerative disease. In AD brain, the aggregation of abnormally hyperphosphorylated NFs into neurofibrillary tangles and extensive neuronal loss are the two major characteristics ${ }^{1-3}$.

Neurofilaments (NFs) are the intermediate filaments (10 $\mathrm{nm}$ diameter) and the most abundant cytoskeletal components, which are assembled from three NF subunits, termed light (NF-L), medium (NF-M) and heavy (NF-H) chains ${ }^{4}$. The hyperphosphorylation and accumulation of NFs are the AD early pathological change contributing to the retrograde degeneration of neurons. In addition to phosphorylation, NFs are also competitively modified by O-GlcNAcylation, a special type of O-glycosylation by which $\beta$-N-acetylglucosamine (GlcNAc) is linked to the serine or threonine residues via an O-linked glycosidic bond $^{5-8}$. Our previous observations that phosphorylation of NFs was inversely regulated by O-GlcNAcylation along with NFs decreased O-GlcNAcylation in AD brain suggest that decrease of O-GlcNAcylation may contributed to the hyperphosphorylation of NFs in neurodegeneration. The O-GlcNAc transferase (OGT) transfering O-GlcNAc and the $\beta$-N-acetylglucosaminidase (O-GlcNAcase) cleav- ing the glycosidic bond are the two important enzymes responsible for the dynamic cycling of O-GlcNAc (ref. $\left.{ }^{9}\right)$.

However, up to now, the role of O-GlcNAcylation in nervous system and O-GlcNAcylation of NFs in SK-NSH cells are little known and need further research. In this study, we tried to decrease the O-Glycosylation by alloxan, an OGT inhibitor ${ }^{10}$ and increase that by NAGthiazolines (NAG-Ae), an O-GlcNAcase inhibitor ${ }^{11}$, to investigate the effects of O-GlcNAc alteration on $\mathrm{AD}$ like hyperphosphorylation and cell loss in neuroblastoma SK-N-SH cells. Our results demonstrated that increasing O-GlcNAcylation with NAG-Ae played a protective role in $\mathrm{AD}$ like neurodegeneration including NFs hyperphosphrylation and the cell loss. These findings provide a potential therapeutic approach for AD by inhibiting O-GlcNAc removal.

\section{MATERIALS AND METHODS}

\section{Cell culture}

Human SK-N-SH neuroblastoma cells were cultured in DMEM/F12 (1:1) Medium (Gibco, MD, USA) supplemented with $10 \%$ fetal bovine serum, $100 \mathrm{IU} / \mathrm{mL}$ Penicillin, $100 \mathrm{IU} / \mathrm{mL}$ streptomycin at $37{ }^{\circ} \mathrm{C}$ at $5 \% \mathrm{CO}_{2}$ atmosphere. 


\section{Western Blots}

Protein concentrations were measured by the BCA protein Assay kit (Beyotime Institute of Biotechnology, Shanghai, China). Proteins from cells were separated by SDS-PAGE and transferred onto a PVDF membrane. After the block with $5 \%$ milk for 30 min, the membranes were incubated with primary antibodies SMI31 (Sternberger Monoclonals, MD, USA), RL2 (abcam, Cambridge, MA, USA), R61d (Institute for Basic Research, New York, USA) against NFs and actin (Beyotime Institute of Biotechnology, Shanghai, China) overnight at $4^{\circ} \mathrm{C}$, and then incubated with secondary antibodies for 2 hours at room temperature. After washing with PBS, the membrane was reacted with BeyoECL Plus reagent and was then scanned. The intensities of the bands were measured using Image $\mathrm{J}$ analysis software.

\section{Immunofluorescence}

The SK-N-SH cells plated on poly L-lysine-coated 8-chamberred glass slides were subjected to various treatment. One was that different concentration of alloxan $(0$, 4, $6 \mathrm{mM}$ ) was added to each chamber and incubated at 37 ${ }^{\circ} \mathrm{C}$ for $12 \mathrm{~h}$. And for another, the cells was preincubated $20 \mu \mathrm{M}$ NAG-Ae for $12 \mathrm{~h}$ before $6 \mathrm{mM}$ alloxan was added. Then, cells were fixed for $20 \mathrm{~min}$ in $10 \%$ neutral formaldehyde on ice. After permeabilization with $0.5 \%$ Triton X-100 for 20 min, cells were treated with 3\% hydrogen peroxide to block endogenous peroxidase and incubated with 5\% BSA for $20 \mathrm{~min}$. Then, cells were incubated with primary antibodies SMI31/NF160, RL2/NF160 at $4{ }^{\circ} \mathrm{C}$ overnight. After that, cells were washed with PBS and incubated with secondary antibodies, FITC-labeled goat anti- mouse IgG, Cy3-labeled goat anti-rabbit IgG (Invitrogen, NM, USA) for $30 \mathrm{~min}$ at $37{ }^{\circ} \mathrm{C}$. Then the glides were covered with anti-fade mounting medium.

\section{PI/Hoechst staining}

PI/Hoechst staining was used to assess cell death. SK-N-SH cells were plated in an 8-chamberred glass slides at a density of $2 \times 10^{4} / \mathrm{mL}$. When the cell quantity reached to $50 \%-60 \%$ per chammber, alloxan and/or NAG-Ae were added to each chamber and incubated at $37{ }^{\circ} \mathrm{C}$. After culture, the medium was removed and $5 \mu \mathrm{L}$ Hoechst/PI (propidium iodide) staining solution was added in proper order, incubated at $4{ }^{\circ} \mathrm{C}$ for $30 \mathrm{~min}$ and then observed under fluorescence microscope.

\section{DAPI staining}

The SK-N-SH cells were plated at a density of $5 \times 10^{3}$ cells in 8-chamberred glass slides coated with poly-D-Lysine. At $24 \mathrm{~h}$ after plating, alloxan and/or NAG-Ae were added to each chamber and incubated at $37{ }^{\circ} \mathrm{C}$. After incubation, cells were fixed in $10 \%$ neutral formaldehyde on ice for $20 \mathrm{~min}$ and then $100 \mathrm{ng} / \mathrm{mL}$ DAPI (4', 6-di-
A

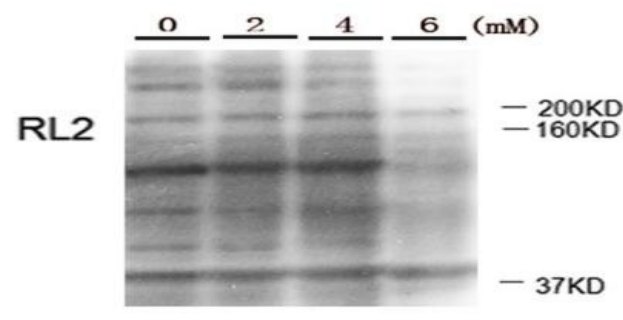

actin

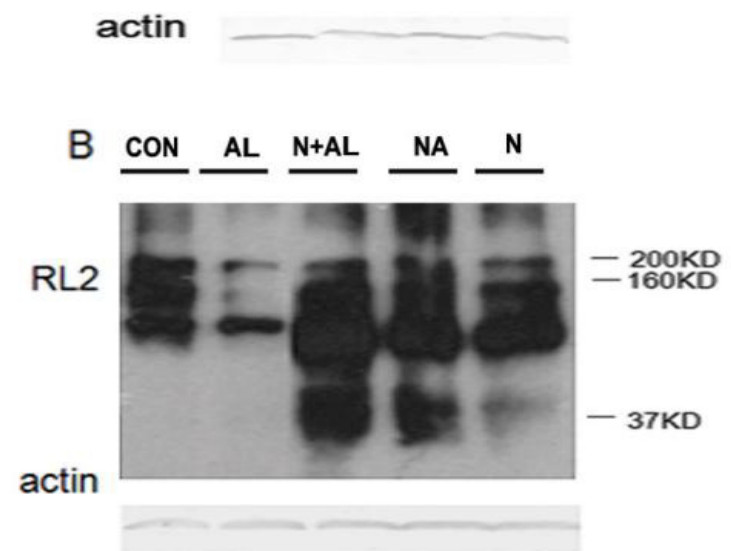

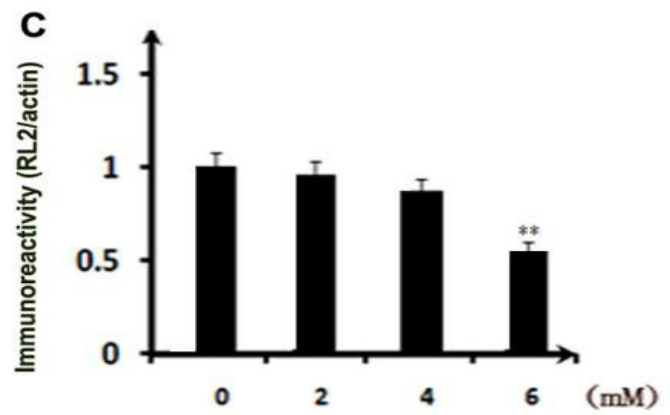

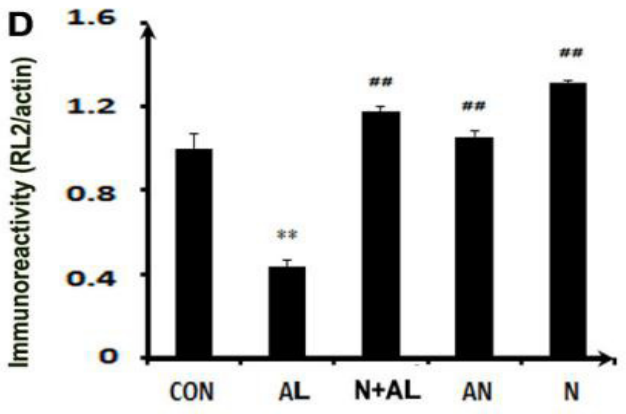

Fig. 1. The O-GlcNAc in alloxan or/and NAG-Ae treated SK-N-SH cells.

A. Representative blots of cells treated with different concentration of alloxan (AL) (0, 2, 4, $6 \mathrm{mM})$ and with specific monoclonal antibodies of RL2 and actin recognized the O-Glycosylation and $\beta$-actin.

B. Representative O-GlcNac blots of cells pretreatment with $20 \mu \mathrm{M}$ NAG-Ae (N+AL) or treated with $20 \mu \mathrm{M}$ NAG-Ae and $6 \mathrm{mM}$ alloxan (NA) at the same time with antibodies RL2 and $\beta$-actin.

C. and D. The quantities assay of blot A. and B.

**indicated $P<0.01$ compared to the control cells. ${ }^{\# \# ~} P<0.01$ compared to alloxan treated cells for the same treatment time. 

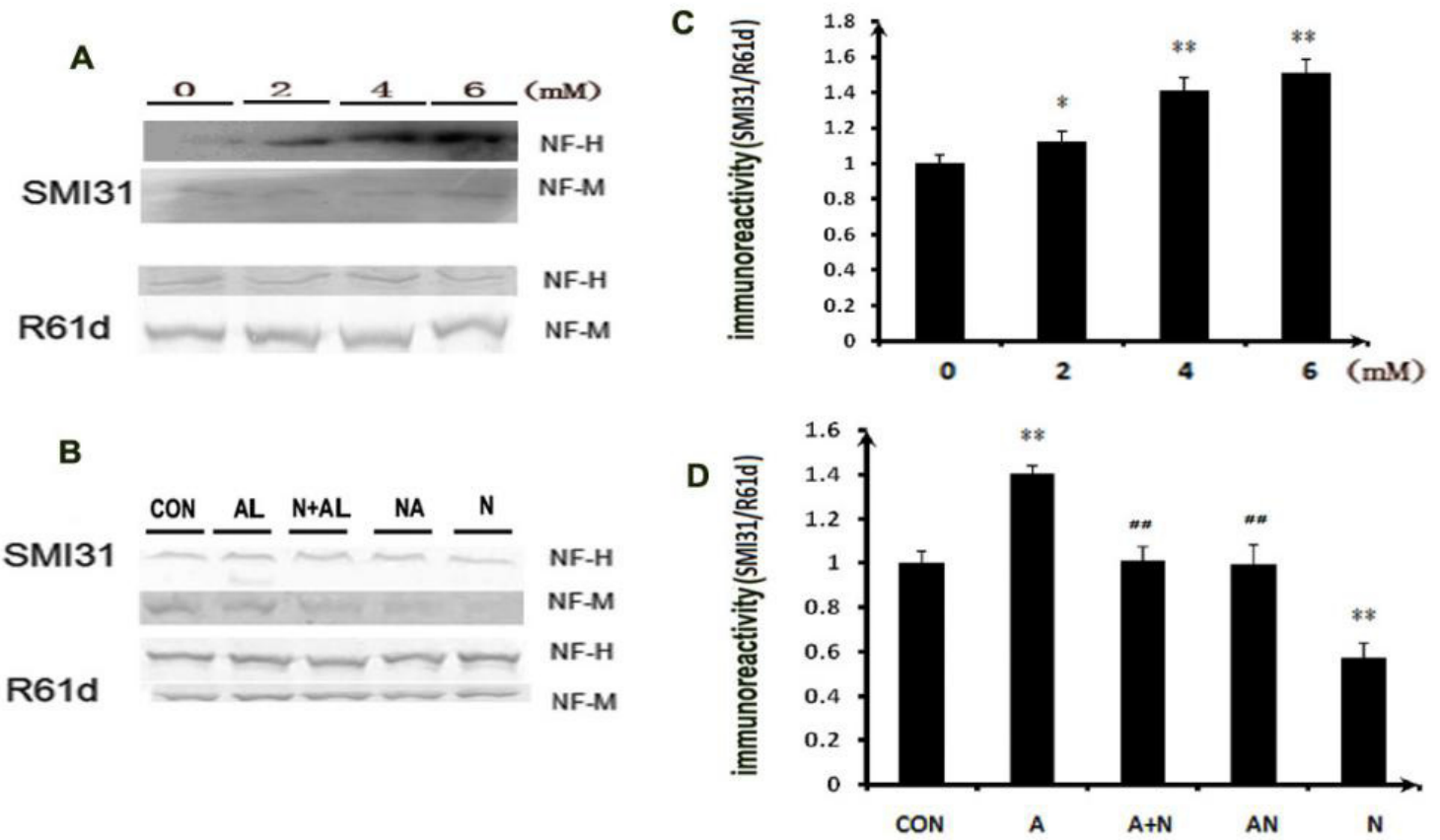

Fig. 2. The abnormal phosphorylation of NFs and accumulation in SK-N-SH cells.

A. Representative blots of cells treated with different concentration of alloxan (AL) $(0,2,4,6 \mathrm{mM})$ with specific monoclonal antibodies of SMI31 and R61d recognized the phorsphorylation and total of NF-M/H.

B. Representative blots of cells pretreatment with $20 \mu \mathrm{M}$ NAG-Ae $(\mathrm{N}+\mathrm{AL})$ or treated with $20 \mu \mathrm{M}$ NAG-Ae and $6 \mathrm{mM}$ alloxan at the same time (NA) with antibodies of SMI31 and R61d

C. and D. The quantities assay of blot A and B

* indicated $P<0.05 * * P<0.01$ compared to the control cells. ${ }^{\# \#} P<0.01$ compared to alloxan treated cells for the same treatment tim

amidino-2-phenylindole) was added and incubated for 2 min. Then the slides were covered with antifade mounting medium and observed under fluorescence microscope.

\section{Statistical analysis}

Experimental data is expressed as means \pm standard deviation $(\bar{x} \pm \mathrm{SD})$. Statistical analyses were performed using one-way analysis of variance (ANOVA) followed by unpaired t-test for data (SPSS16.0, La Jolla, CA). Significant differences between experimental groups were defined as $\mathrm{P}<0.05$.

\section{RESULTS}

\section{Alloxan and NAG-Ae causes reverse change in the level of O-GlcNAcylation in SK-N-SH cells}

We detected the level of O-GlcNAcylation with antibody RL2 to recognize the O-Glycosylation of protein in cells treated with alloxan and NAG-Ae. Compared to the control, the level of O-GlcNAcylation was decreased in a dose-dependent manner as the cells exposed to alloxan (Fig. 1A, B). It was increased as cells exposed to NAGAe, while reduced level of O-GlcNAcylation induced by alloxan was recovered by the treatment of $20 \mu \mathrm{M}$ NAG-Ae (Fig. 1C, D).

\section{Increased O-GIcNAcylation induces decreased phosphorylation of NFs in SK-N-SH cells}

In order to observe the phosphorylation of NFs, specific antibody SMI31 and R61d were used to detect the phosphorylated tail domain of NF-M/NF-H and total NFs. The phosphorylation of NF-M/NF-H was increased by the treatment of alloxan in concentration-dependent manner, but the total of NFs that was detected by monoclonal antibody R61d had not changed (Fig. 2A, B). Furthermore, when the cells were pretreated with $20 \mu \mathrm{M}$ NAG-Ae for $12 \mathrm{~h}$, or treated with $20 \mu \mathrm{M}$ NAG-Ae and $6 \mathrm{mM}$ alloxan at the same time, the phosphorylation of $\mathrm{NF}-\mathrm{H} / \mathrm{M}$ induced by alloxan was reduced by both pretreatment and treatment of NAG-Ae. The difference is that NAG-Ae pretreatment showed a stronger protective role for abnormal NFs phosphorylation (Fig. 2C, D).

We also observed a dose-dependent decrease in O-GlcNAcylation of NF-M, as determined by monoclonal antibody NL6. Immunofluorence staining of these cells indicated that alloxan treatment markedly increased SMI31 staining, decreased NL6 staning and caused accumulation of the phosphorylated NF in the cells (Fig. 3A, B). Consistent with the results of western blot, NAG-Ae treatment protected SK-N-SH cells from the morphology change and abnormal phosphorylation (Fig. 3C, D). Taken together, these results suggested that O-GlcNAcylation and phosphorylation of NFs are regulated reciprocally in SK-N-SH cells and that increased 


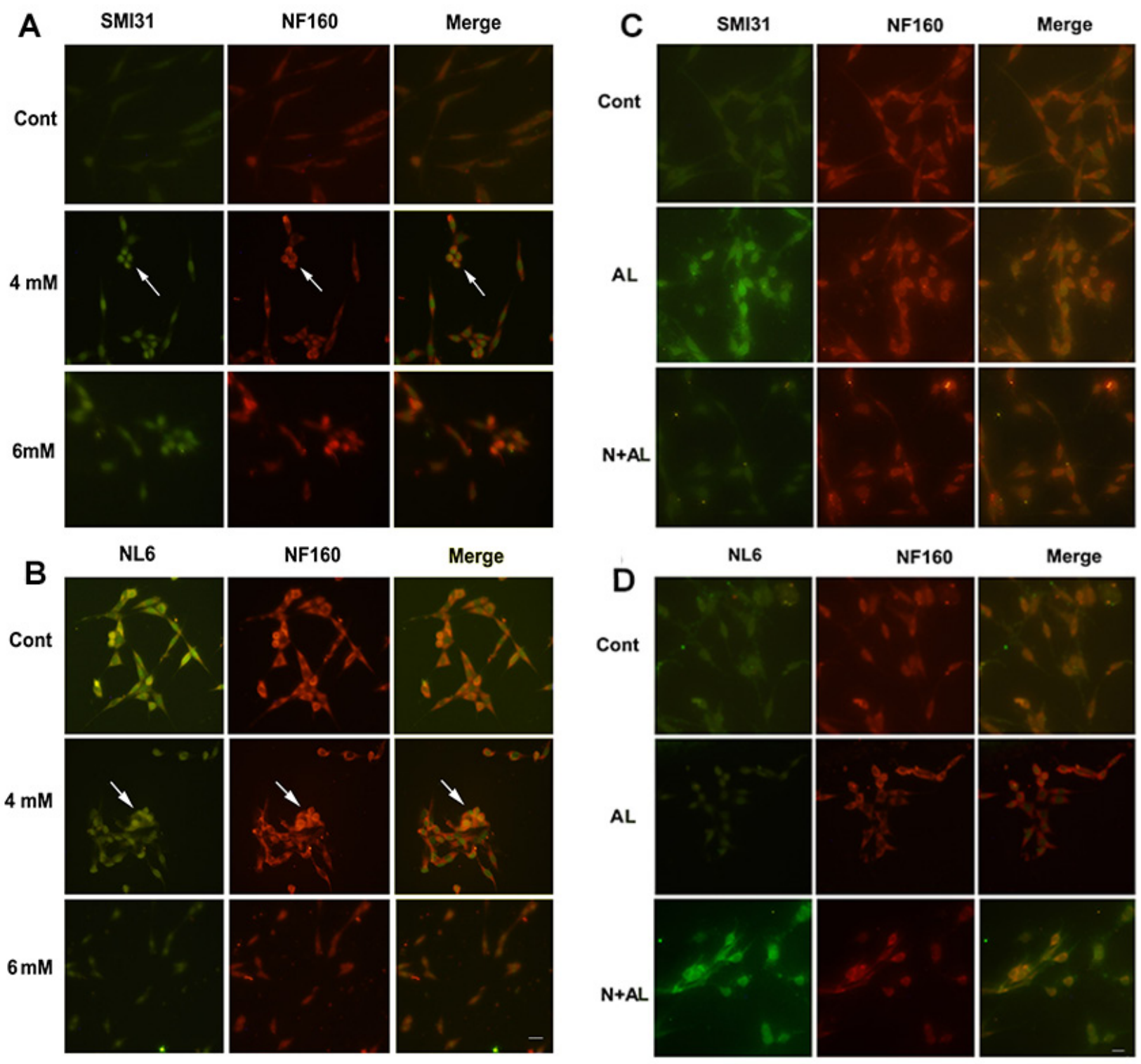

Fig. 3. The localization assay of O-GlcNAc and phosphorylation in SK-N-SH cells.

Representative pictures of Immunofluorescence in cells were treated with 4, $6 \mathrm{mM}$ alloxan (A and B) or $20 \mu \mathrm{M}$ NAG-Ae pretreatment (C and D) with antibodies SMI31/NF160 or NL6/NF160, arrow indicated cells to be round with accumulated NF.

Scale $100 \mu \mathrm{m}$.

O-GlcNAcylation with NAG-Ae protected NFs from abnormal phosphorylation.

The effects of phosphorylation and O-GlcNacylation on cells death

Cells death was assessed by Hoechst(Ho)/PI staining and DAPI staining since PI is excluded by viable cells and Ho can penetrate cell membranes. Apoptotic cells show a high Ho staining and a low PI staining (strong blue fluorescence and light red fluorescence), and necrotic cells are brightly stained with PI and Ho (strong blue fluorescence and strong red fluorescence). Healthy cells are dimly stained by Ho and not stained by PI, so the control cells showed light blue fluorescence without red fluorescence. We found that $4 \mathrm{mM}$ and $6 \mathrm{mM}$ alloxan treat- ment induced cells apoptosis and necrosis respectively (Fig. 4A). By contrast, cells exposed to NAG-Ae were similar to the control cells. Additionally, pretreatment of the cells with NAG-Ae reduce the staining of strong blue and strong red fluorescence induced by $6 \mathrm{mM}$ alloxan treatment (Fig. 4B).

In DAPI staining, alloxan treatment can cause cell apoptosis, while cells with treated or pretreated with NAG-Ae displayed no abnormal changes (Fig. 4C). The staining results suggest that increased phosphorylation with alloxan treatment induced cells apoptosis and necrosis. Increased O-GlcNacylation with NAG-Ae treatment or pretreatment, on the contrary, reduced cell death which was induced by alloxan in SK-N-SH cells. 


\section{DISCUSSION}

Many studies have demonstrated that O-GlcNAcylation and phosphorylation competitively modify the same serine/threonine residues and are thus reciprocal to each other. Especially in the central nervous system, O-GlcNAcylation has also been shown to regulate many synaptic proteins and neuronal cytoskeleton proteins ${ }^{12,13}$. We also found that impaired glucose uptake/ metabolism can lead to hyperphosphorylation and pathological accumulation of NFs in AD brain by decreased O-GlcNAcylation ${ }^{14}$.

What's more, different ways of modulating the O-GlcNAcylation levels may cause conflicting results. In the present study, by using alloxan (OGT inhibitor) and NAG-Ae (OGA inhibitor) to change the O-GlcNAcylation levels in cultured neuroblastoma cells, the interrelationship similar to early studies between O-GlcNAcylation and phosphorylation of NFs was detected; This is to say, increased O-GlcNAcylation protects NFs from abnormal phosphorylation ${ }^{15}$. However, except OGT, alloxan has also been shown to inhibit the glucokinase and GlcNAcase of pancreatic $\beta$-cell, the effect of several protein phosphatase and kinase such as phosphatase 2A (PP2A), glycogen synthesis kinase 3 (GSK-3), cyclin-dependent kinase 5 (CDK5), mitogen-activated protein kinase (MAPK), stress-activated protein kinase family (SAPK1), calcium/ calmodulin-dependent protein kinase II (CaMKII) should be taken into account ${ }^{10,16,17}$.

NAG-Ae was a more potent and selective inhibitor of O-GlcNAcase, research indicated that it has cardioprotective effects on acute ischemic myocardium by preserving the integrity of Z-line protein via increased O-GlcNAcylation ${ }^{19}$. Howewer, whether NAG-Ae could protect the neuronal cells is not clear. In our test, we found $20 \mu \mathrm{M}$ NAG-Ae inhibited the abnormal phosphorylation and accumulation of NF in the bodies, but the cell viability was decreased in concentration of $80 \mu \mathrm{M}$ and $160 \mu \mathrm{M}$ NAG-Ae (Data not shown). Besides, hyperO-GlcNAcylation leads to impaired memory and synaptic plasticity ${ }^{20}$. Thus, selection of proper dose and time may be the key point to develop reagents to improve the O-GlcNAc for AD therapy.

Cell loss is another one of the pathological features in $\mathrm{AD}$ brain. In our test, we found apoptotic morphology changes of nuclear condensation or fragmentation with alloxan treatment. In addition, the apoptosis was accompanied by hyperphosphorylation of NFs, as aggregation of phosphorylated tau is thought as the cause of apopto$\operatorname{sis}^{21}$. However, other investigators found that the reduced number of neurons in AD is actually neuronal apoptosis induced by increased O-GlcNAcylation via AKT signaling and NFKB (ref. ${ }^{22,23}$ ). As far as now, the fate of cells with hyperphosphorylation and early apoptosis feature is hardly understood.
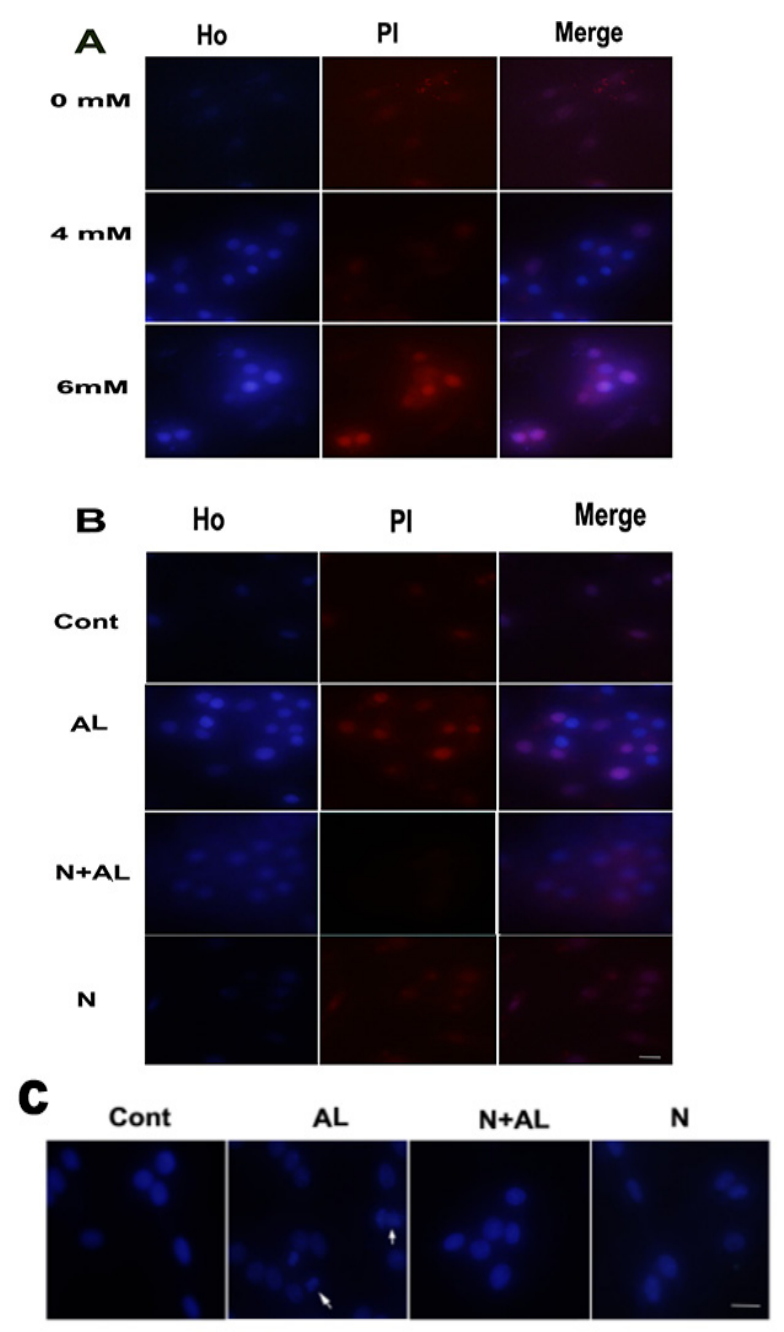

Fig. 4. Representative pictures of Hoechst (Ho)/PI staining and DAPI staining.

A. Cells exposed to different concentration of alloxan $(0,4,6$ $\mathrm{mM}$ ) for $12 \mathrm{~h}$ were stained by Ho/PI.

B. Cells exposed to $6 \mathrm{mM}$ alloxan with or without pretreatment of NAG-Ae stained by PI/Hoechst staining.

C. Cells exposed to $6 \mathrm{mM}$ alloxan with or without pretreatment of NAG-Ae $(\mathrm{N}+\mathrm{AL})$ or NAG-Ae $(\mathrm{N})$ only were stained by DAPI. Arrow indicated the nuclear condensation or fragmentation.

Scale $100 \mu \mathrm{m}$.

\section{CONCLUSION}

In summary, increasing O-GlcNAc with NAG-Ae protected Alzheimer-like neurodegeneration from NFs hyperphosphrylation and the cell loss, suggesting the role of decreased O-GlcNAc in the pathogenesis of AD. As a result, the inhibition of O-GlcNAc removal may represent a new therapeutic approach for AD.

Acknowledgements: This research was supported by grants from the National Natural Science Foundation of China (30973156, 81270422), the National Institutes of Health (NIH)/Fogarty International Research Collaboration Award (FIRCA) of the US (R03 TW008123) and the 
National and Tianjin Training Programs of Innovation and Entrepreneurship for Undergraduates (201610062013, 201710062029).

Author contributions: ND: performed the experiments; PP: manuscript writing; YC, JW, SC: data analysis; RA: language correction; YD: experiments design, final revision.

Conflict of interest statement: None declared.

\section{REFERENCES}

1. Perry G, Rizzuto N, Autilio-Gambetti L, Gambetti P. Paired helica filaments from Alzheimer disease patients contain cytoskeletal components. Proc Natl Acad Sci USA 1985;82(11):3916-20.

2. Sternberger $\mathrm{NH}$, Sternberger LA, Ulrich J. Aberrant neurofilament phosphorylation in Alzheimer disease. Proc Natl Acad Sc USA;82(12):4274-6.

3. Black MM, Lee VM-Y. Phosphorylation of neurofilament proteins in intact neurons: Demonstration of phosphorylation in cell bodies and axons. J Neurosci 1988;8:3296-305.

4. Wang $H$, Wu M, Zhan $C$, Ma E, Yang M, Yang $X$, Li Y. Neurofilament proteins in axonal regeneration and neurodegenerative diseases. Neural Regen Res 2012;7:620-6.

5. Rao MV, Yuan A, Campbell J, Kumar A, Nixon RA. The C-Terminal Domains of NF-H and NF-M Subunits Maintain Axonal Neurofilament Content by Blocking Turnover of the Stationary Neurofilament Network. Yang Y, ed. PLoS ONE. 2012;7(9):e44320.

6. Deng Y, Li B, Liu Y, lqbal K, Grundke-lqbal I, Gong C-X. Dysregulation of insulin signaling, glucose transporters, O-GIcNAcylation, and phosphorylation of tau and neurofilaments in the brain: Implication for Alzheimer's disease. Am J Pathol 2009;175(5):2089-98.

7. Dale JM, Garcia $\mathrm{mL}$. Neurofilament phosphorylation during development and disease: which came first, the phosphorylation or the accumulation? J Amino Acids 2012;2012:382107.

8. Kang MJ, Kim $C$, Jeong $H$, Cho B-K, Ryou AL, Hwang $D$, Yi EC. Synapsin-1 and tau reciprocal O-GlcNAcylation and phosphorylation sites in mouse brain synaptosomes. Exp Mol Med 2013;45(6):e29.

9. Perry G, Rizzuto N, Autilio-Gambetti L, Gambetti P. Paired helical filaments from Alzheimer disease patients contain cytoskeletal components. Proc Natl Acad Sci USA 1985;82(11):3916-20.

10. Konrad RJ, Zhang F, Hale JE, Knierman MD, Becker GW, Kudlow JE. Alloxan is an inhibitor of the enzyme O-linked $\mathrm{N}$-acetylglucosamine transferase. Biochem Biophys Res Commun 2002;293(1):207-12.

11. Krejzová J, Simon $P$, Kalachova L, Kulik N, Bojarová $P$, Marhol P,
Pelantová H, Cvačka J, Ettrich R, Slámová K, Křen V. Inhibition of glcnac-processing glycosidases by c-6-Azido-nag-thiazoline and its derivatives. Molecules 2014;19(3):3471-88.

12. Liu Y, Li X, Yu Y, Shi J, Liang Z, Run X, Li Y, Dai CL, Grundke-lqbal I, Iqbal K, Liu F, Gong CX. Developmental Regulation of Protein O-GIcNAcylation, O-GIcNAc Transferase, and O-GlcNAcase in Mammalian Brain. Planel E, ed. PLoS ONE 2012;7(8):e43724.

13. Zeidan Q, Hart GW. The intersections between O-GlcNAcylation and phosphorylation: implications for multiple signaling pathways. J Cell Sci 2010;123(1):13-22.

14. Deng Y, Li B, Liu F, lqbal K, Grundke-lqbal I, Brandt R, Gong CX. Regulation between O-GIcNAcylation and phosphorylation of neurofilament-M and their dysregulation in Alzheimer disease. FASEB J 2008;22(1):138-45.

15. Gong C, Liu F, lqbal K. O-GlcNAcylation: A regulator of tau pathology and neurodegeneration. Alzheimer's Dement 2016;12(10):1078-89. doi: 10.1016/j.jalz.2016.02.011

16. Ogunnowo-Bada EO, Heeley N, Brochard L, Evans mL. Brain glucose sensing, glucokinase and neural control of metabolism and islet function. Diabetes, Obes Metab 2014;16:26-32.

17. Taylor EW, Wang K, Nelson AR, Bredemann TM, Fraser KB, Clinton SM Puckett R, Marchase RB, Chatham JC, McMahon LL. O-GlcNAcylation of AMPA receptor GluA2 is associated with a novel form of long-term depression at hippocampal synapses. J Neurosci 2014;34(1):10-21.

18. Gloster TM, Vocadlo DJ. Mechanism, Structure, and Inhibition of O-GlcNAc Processing Enzymes. Curr Signal Transduct Ther 2010;5(1):74-91.

19. Laczy B, Marsh SA, Brocks CA, Wittmann I, Chatham JC. Inhibition of $O$-GIcNAcase in perfused rat hearts by NAG-thiazolines at the time of reperfusion is cardioprotective in an O-GlcNAc-dependent manner. Am J Physiol Hear Circ Physiol 2010;299:H1715-H1727.

20. Yang $Y R$, Song $S$, Hwang $H$, Jung JH, Kim SJ, Yoon $S$, Hur JH, Park Jl, Lee C, Nam D, Seo YK, Kim JH, Rhim H, Suh PG. Memory and synaptic plasticity are impaired by dysregulated hippocampal O-GIcNAcylation. Scientific Reports 2017;7:44921.

21. Buée L, Troquier $L$, Burnouf $S$, Belarbi K, Van der Jeugd $A$, Ahmed T, Fernandez-Gomez F, Caillierez R, Grosjean ME, Begard S, Barbot B, Demeyer D, Obriot H, Brion I, Buée-Scherrer V, Maurage CA, Balschun D, D'hooge R, Hamdane M, Blum D, Sergeant N. From tau phosphorylation to tau aggregation: what about neuronal death? Biochem Soc Trans 2010;38(4):967-72.

22. Shi J, Gu JJJ-H, Dai C, Dai CL, Gu J, Jin X, Sun J, Iqbal K, Liu F, Gong CX. O-GlcNAcylation regulates ischemia-induced neuronal apoptosis through AKT signaling. Sci Rep 2015;5:14500

23. Kim S, Yoo W, Choi M, Chung I, Yoo J, Choi W. Increased O-GlcNAcylation of NF- i B Enhances Retinal Ganglion Cell Death in Streptozotocin-induced Diabetic Retinopathy. Curr Eye Res 2015;0(0):1-9. 